\title{
Specificity Protein 1 Expression Contributes to Bcl-w-Induced Aggressiveness in Glioblastoma Multiforme
}

\author{
Woo Sang Lee, Junhye Kwon ${ }^{1}$, Dong Ho Yun, Young Nam Lee, Eun Young Woo, Myung-Jin Park, \\ Jae-Seon Lee, Young-Hoon Han, and In Hwa Bae*
}

\begin{abstract}
We already had reported that Bcl-w promotes invasion or migration in gastric cancer cells and glioblastoma multiforme (GBM) by activating matrix metalloproteinase-2 (MMP-2) via specificity protein 1 (Sp1) or $\beta$-cateinin, respectively. High expression of $\mathrm{Bcl}-\mathrm{w}$ also has been reported in GBM which is the most common malignant brain tumor and exhibits aggressive and invasive behavior. These reports propose that Bcl-w-induced signaling is strongly associated with aggressive characteristic of GBM. We demonstrated that $\mathrm{Sp} 1$ protein or mRNA expression is induced by Bcl-w using Western blotting or RT-PCR, respectively, and markedly elevated in high-grade glioma specimens compared with low-grade glioma tissues using tissue array. However, relationship between Bcl-w-related signaling and aggressive characteristic of GBM is poorly characterized. This study suggested that Bcl-w-induced Sp1 activation promoted expression of glioma stem-like cell markers, such as Musashi, Nanog, Oct4 and sox-2, as well as neurosphere formation and invasiveness, using western blotting, neurosphere formation assay, or invasion assay, culminating in their aggressive behavior. Therefore, Bcl-w-induced Sp1 activation is proposed as a putative marker for aggressiveness of GBM.
\end{abstract}

\section{INTRODUCTION}

Glioblastoma multiforme is the most common and lethal type of malignant brain tumor, exhibiting highly proliferative growth and widespread invasive potential, culminating in vigorous tumor progression. Despite the commonly available treatments of surgical resection, radiation and chemotherapy, GBM is difficult

Division of Radiation Cancer Research, Korea Institute of Radiological \& Medical Sciences, Seoul 139-706, Korea, 'Department of Biological Sciences, Sookmyung Women's University, Seoul 140-742, Korea

${ }^{*}$ Correspondence: ihbae@kirams.re.kr

Received 28 May, 2013; revised 11 October, 2013; accepted 26 November, 2013; published online 27 January, 2014

Keywords: aggressiveness, Bcl-w, glioblastoma multiforme, glioma stem cell markers, invasion, Sp1 to treat because of its high frequency of recurrence (Furnari et al., 2007).

Current evidence suggests that the B-cell lymphoma 2 homo$\log (\mathrm{Bcl}-\mathrm{w})$ enhances cell survivability through its anti-apoptotic activity, as well as the migratory and invasive potential of cancer cells. Bcl-w is expressed in a variety of cancer types, including gastric cancer (Lee et al., 2003), colorectal adenocarcinomas (Wilson et al., 2000) and glioblastoma multiforme (Hoelzinger et al., 2005; Lee et al., 2013), in a cancer cell-specific manner. We have previously reported that Bcl-w enhances migratory and invasive potential in gastric cancer cells by inducing the production of several types of extracellular matrix (ECM)degrading proteinases (Bae et al., 2006; 2009). These observations support the claim that expressions of Bcl-w-induced signaling components in GBM are strongly correlated with GBM invasiveness. Growing evidence indicates that, in addition to Bcl-w expression, Sp1 and MMP-2 expressions are upregulated in glioma tissue. Specially, Sp1 plays a critical role in the regulation of multiple genes implicated in tumorigenesis (Safe and Abdelrahim, 2005). In several human cancer types, including breast cancer (Zannetti et al., 2000), thyroid tumor (Chiefari et al., 2002), gastric cancer (Yao et al., 2004), epidermal squamous cell carcinoma (Kumar and Butler, 1999) and pancreatic cancer (Shi et al., 2001), an elevation of Sp1 expression levels has been reported, which, in some instances, has been correlated with poor clinical diagnosis (Guan et al., 2011; Wang et al., 2003). Sp1 transcriptional activity is crucial role for tumor progression such as proliferation, tumor formation, migration, mesenchymal transition, angiogenesis and metastasis in various human cancer cell types (Abdelrahim et al., 2004; Jungert et al., 2007; Lou et al., 2005; Shin et al., 2011; Wang et al., 2005; Wei et al., 2004).

However, no study, to our knowledge, has examined the relationship between glioma cell characteristics and upregulated proteins, such as Bcl-w, Sp1 and MMP-2 in glioma. Based on our findings, we conclude that Bcl-w-induced Sp1 expression is critical for the development of GBM characteristics, because it functions as a positive regulator for the maintenance of stemness. Therefore, our data suggest that Bcl-w and Sp1 represent potential prognostic markers for glioma progression. 


\section{MATERIALS AND METHODS}

Cell culture, transfection, and treatments

The U251 were obtained from the Korean Cell Line Bank (KCLB) and cultured in Minimum Essential Medium Eagle (MEM) (Mediatech, Inc., USA) containing 10\% fetal bovine serum (FBS) (Tissue Culture Biologicals, USA) and penicillin-streptomycin antibiotics (PAA Laboratories $\mathrm{GmbH}$, Austria) under a humidified $5 \% \mathrm{CO}_{2}$ incubator at $37^{\circ} \mathrm{C}$. U251 cells were transfected with either empty pcDNA vector or that Bcl-w cDNA. The control and $\mathrm{Bcl}-\mathrm{w}$-overexpressing cells were transiently transfected using Lipofectamine 2000 or RNAi MAX (Invitrogen, USA) with the indicated expression constructs or chemically synthesized small interfering RNAs (siRNAs). Small interfering RNAs were purchased from as the following; silencer negative control siRNA, si-Bcl-w (Ambion, USA), si-Sp1 and si-MMP-2 (Santa Cruz Biotechnology, USA).

\section{Western blot analysis}

The cells were lysed in a buffer containing $50 \mathrm{mM}$ HEPES, $\mathrm{pH}$ 7.4, $100 \mathrm{mM} \mathrm{NaCl}, 1 \%$ Triton X-100, 10\% glycerol, $1 \mathrm{mM}$ EDTA, $20 \mathrm{mM} \beta$-glycerophosphate, $5 \mathrm{mM} \mathrm{NaF}, 2 \mu \mathrm{g} / \mathrm{ml}$ aprotinin, 2 $\mathrm{ug} / \mathrm{ml}$ leupeptin and $100 \mathrm{mM}$ phenylmethylsulfonyl fluoride. Prepared cell lysates were subjected to SDS-PAGE and electrotransferred to Immobilon membranes (Millipore, USA), then that incubated with the indicated antibodies and visualized by the ECL detection system (Advansta, USA).

\section{Antibodies and inhibitors}

The antibodies were used as follows; anti-Sp1 was purchased from Santa Cruz Biotechnology (USA). Anti-Bcl-w and antiMusashi were obtained from Cell Signaling technology (USA). Anti- $\beta$-actin was purchased from Sigma-Aldrich (USA). AntiOct3/4 was obtained from Novous Biologicals (Vittleton, Co). Anti-Nanog was purchased from Chemicon International (USA). Anti-Sox-2 was purchased from $R$ \& D Syetems (USA). AntiMMP-2was obtained from Calbiochem (USA). The pharmacological inhibitors were used in this study; mithramycin A (MMA) was purchased from Sigma-Aldrich (USA). Oleoyl-N-hydroxylamide (OA-Hy) was obtained from Calbiochem (USA).

\section{Quantitative reverse transcription polymerase chain reaction (RT-PCR) analysis}

Total RNA was isolated from cultured U251 cells using TriZol (MRC Gene, USA), of which 100 ng was converted to cDNA with reverse transcriptase. EconoTaq PLUS GREEN 2x master mix (Lucigen, USA) was added to the reaction mix, and quantitative RT-PCR analysis was performed using primers for Sp1: forward 5'-TTG AAA AAG GAG TTG GTG GC-3', reverse 5'CTG GTT CTG TAA GTT GGG AG-3', Musashi: forward 5'ACA GCC ATT GGA GAG TGA G-3', reverse 5'-GGT GAA GGC TGT GGC TTA C-3', Nanog: forward 5'-GCT TGC CTT GCT TTG AAG CA-3', reverse 5'-GTT CTT GCA TCT GCT GGA GG-3', Oct4: forward 5'-GAG CAA AAC CCG GAG GAG T-3' reverse 5'-TTC TCT TTC GGG CCT GCA C-3' and Sox-2: forward 5'-ATG CAC CGC TAC GAC GTG A-3', reverse 5'CTT TTG CAC CCC TCC CAT T-3'. Quantitative measurement of mRNA was obtained from 3 independent experiments. The expression levels of mRNAs specific for each gene were normalized to the expression of GAPDH (glyceraldehydes 3-phosphate dehydrogenase).

Invasion assay

These assays were conducted as described previously. The 2 $\times 10^{5}$ cells were seeded onto the Matrigel-coated polycarbonated filters which were placed in modified Boyden chambers (Corning, USA) that contain ECM components (BD Biosciences, USA). After $20-24 \mathrm{~h}$ of incubation at $37^{\circ} \mathrm{C}$, the cells that had invaded to the lower surface of the membrane were fixed and stained using a Diff-Quick kit (Fisher Scientific, USA), then counted under a microscope (Mitoti AE31 series, Trinocular inverted MIC). Five independent experiments were analyzed for statistical significance using the Student's $t$-test. Differences were considered to be statistically significant at $p<0.05$.

\section{Immunohistochemistry}

To determine the levels of endogenous $\mathrm{Sp} 1$ in human brain cancer tissues, premade AccuMax array Brain cancer tissues for formalin fixed paraffin embedded slides (A221- V) were commercially purchased from ISU Abxis Co. LTD. (Korea). The tissue array contained 35 brain cancer specimens, including astrocytoma (WHO grade I), anaplastic astrocytoma (WHO grade III) and glioblastoma multiforme (WHO grade IV). Tissue sections were incubated with REAL Peroxidase-blocking solution (Dako, Cat \# S2023, Denmark A/S produktionsvej 42) to quench endogenous peroxidase activity. Tissues were immunoreacted with anti-Sp1 antibody (Santa Cruz Biotechnology, USA; 1:200). The levels of endogenous Sp1 were stained with 3,3'-diaminobenzidine (DAB) substrate kit for peroxidase (Vector Laboratories, USA) after conjugation using avidin-biotinperoxidase complex (VECTASTATIN Universial Elite ABC Kits; Vector Laboratories, USA). Slides were counterstained with hematoxylin, dehydrated, and mounted with Permount solution (Fisher Scientific, USA). Images were acquired by Olympus BX53Fmicroscopy using cellSens Standard controller software (Olympus). Sp1-positive cells were counted in three different horizontally adjacent fields. The mean of triplicate experiments was significantly different depending on grades of glioma tissues.

\section{Spheres culture}

The vector control or the Bcl-w overexpressing U251 cells were suspended in Dulbecco's modified Eagle's medium-F12 (Cellgro, USA) containing $20 \mathrm{ng} / \mathrm{ml}$ each of epidermal growth factor (EGF, Biovision, USA), basic fibroblast growth factor (bFGF, Biovision) and B27 (1:50) (GIBCO, USA) as a stem-cell-permissive medium. Spheres were harvested after 2 to 4 days and protein extracts were subject to Western blotting with appropriate antibodies.

\section{Sphere formation assay}

For generating sphere formation, sphere cells were dissociated with Accutase (Innovative Cell Technologies, Inc) for expansion. Sphere-forming U251 cells were first distributed into 96-well plates at a density of $1-2$ cells per well. After $12 \mathrm{~h}$, individual wells were visually checked for the presence of a single cell. The clones were grown and tested for the sphere formation. After 20 days until the sphere formation, spheres were attached by $10 \%$ FBS and stained with Coomassie Brilliant Blue R-250 solution (bioWORLD, USA). Sphere with a diameter > 20 um were counted under an inverted microscope using Miotic AE31 series.

\section{Gelatin zymography}

Conditioned media were prepared by incubating cells in serumfree media for $24 \mathrm{~h}$. The media were supplemented with specific inhibitors or targeting siRNA. Equal volumes of conditioned media were then subjected to $8 \%$ SDS-PAGE containing $0.1 \%$ 
A

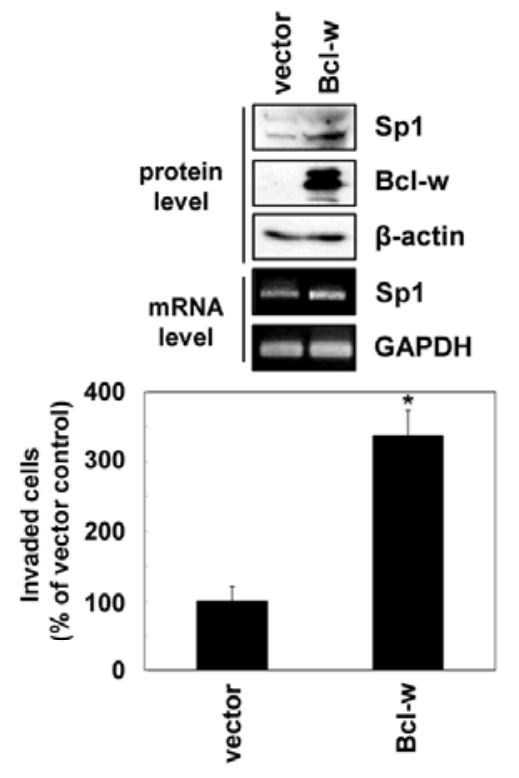

C

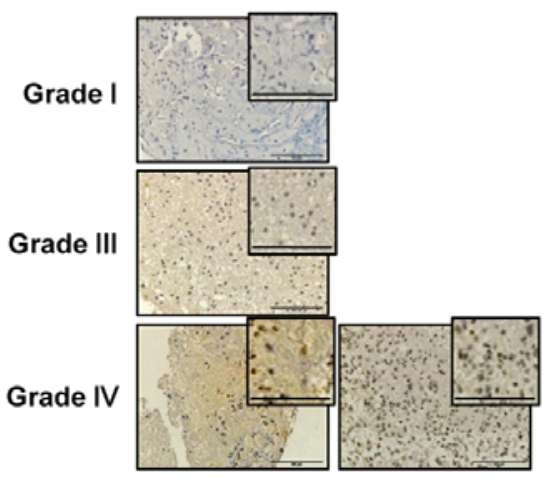

B
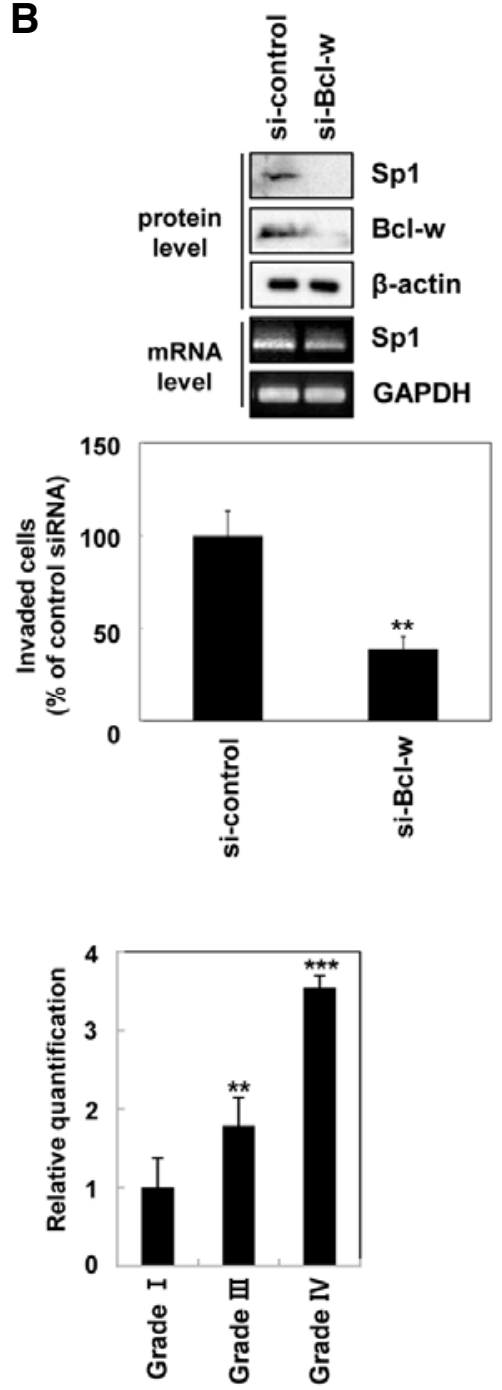

Fig. 1. Bcl-w-induced Sp1 expression is correlated with invasiveness of U251 glioblastoma multiforme cells. (A) U251 cells were transfected with either empty pcDNA vector or that Bcl-w cDNA. The expression levels of $\mathrm{Bcl}-\mathrm{w}$ and $\mathrm{Sp} 1$ were detected using Western blotting or reverse quantitative reverse transcription polymerase chain reaction (RTPCR) analysis with $\beta$-actin or GAPDH (glyceraldehydes 3-phosphate dehydrogenase), respectively, as the loading control. The invasive potential of U251 cells was analyzed by Matrigelcoated polycarbonate filters. Cells were incubated for 20-24 h in modified Boyden chambers, and cells penetrating the filters were stained and counted under a light microscope. The mean of triplicate experiments was significantly different from controls. ${ }^{*} p<0.05$. (B) Bcl-w targeting siRNA was introduced into U251 cells, and Western blotting, RT-PCR or invasion assay was conducted. Experiments were repeated 5 times, and the mean values and standard deviations determined. ${ }^{* *} p<0.005$. (C) Tissue AccuMax microarrays (A221V) from patients with brain cancer were subjected to immunohistochemical staining with anti-Sp1 antibody. Glioma grade I (Patient 1); III (Patient 2); IV (Patient 3, 4). Bar scale, $100 \mu \mathrm{m}$. Sp1positive cells were counted in three different horizontally adjacent fields. The mean of triplicate experiments was significantly different depending on grades of glioma tissues. ${ }^{* *} p<0.005$; ${ }^{\star \star \star} p<0.0005, \mathrm{n}=3$. gelatin. The gels were stained, and the MMPs activities were visualized as clear bands. Ponceau $\mathrm{S}$ staining is as the loading control.

\section{RESULTS}

\section{Bcl-w-induced Sp1 expression is involved in the} invasiveness of GBM

In this study, we investigated the relationship between Bcl-w and Sp1 that resulted in the up-regulation of glioma tissues. To establish the effect of Bcl-w on Sp1 expression and aggressiveness as manifested by invasive potential in glioblastoma, Bcl-w was overexpressed in U251 glioma cells. Bcl-w-overexpressing cells demonstrated enhanced Sp1 protein and mRNA, expression and glioblastoma invasiveness, as measured by an invasion assay using Matrigel-coated polycarbonate filters (Fig. 1A). The Bcl-w-induced invasiveness of cells treated with Bcl-w targeted small interference RNAs (siRNAs) was effectively, attenuated Sp1 protein and mRNA expression and glioblastoma invasiveness (Fig. 1B). These observations strongly suggest that Bcl-w induces the upregulation of Sp1 expression by the transcriptional mechanism. To confirm the pattern of Sp1 expression in various grades of brain cancer tissues (WHO I, III, and IV), we performed a immunohistochemistry assay using premade AccuMax array slides containing 35 specimen from patients with brain tumors. Sp1 expression was up-regulated in glioblastoma tissues (glioma grade IV) compared with glioma tissues (grade I/III) in every sample examined as low/high magnification (Fig. 1C). Notably, the subcellular localization of Sp1, a transcription factor, was apparent primarily in the nucleus, as expected. These results indicate that Sp1 expression levels are closely correlated with tumor grading in patients with glioma.

\section{Bcl-w-induced Sp1 contributes to stemness of glioblastoma} cells

These stemness-related results were used spheres-cultured U251 glioma cells. To examine the effect of Bcl-w-induced Sp1 expression in the enhancement of aggressiveness, Sp1-depleted activation by pharmacological inhibition with mithramycin A (MMA; $10 \mu \mathrm{mol} / \mathrm{L})$ (Fig. 2A) or Sp1 RNA interference (Fig. 2B) attenuated not only sphere-formation of stem-like cell popu- 
A
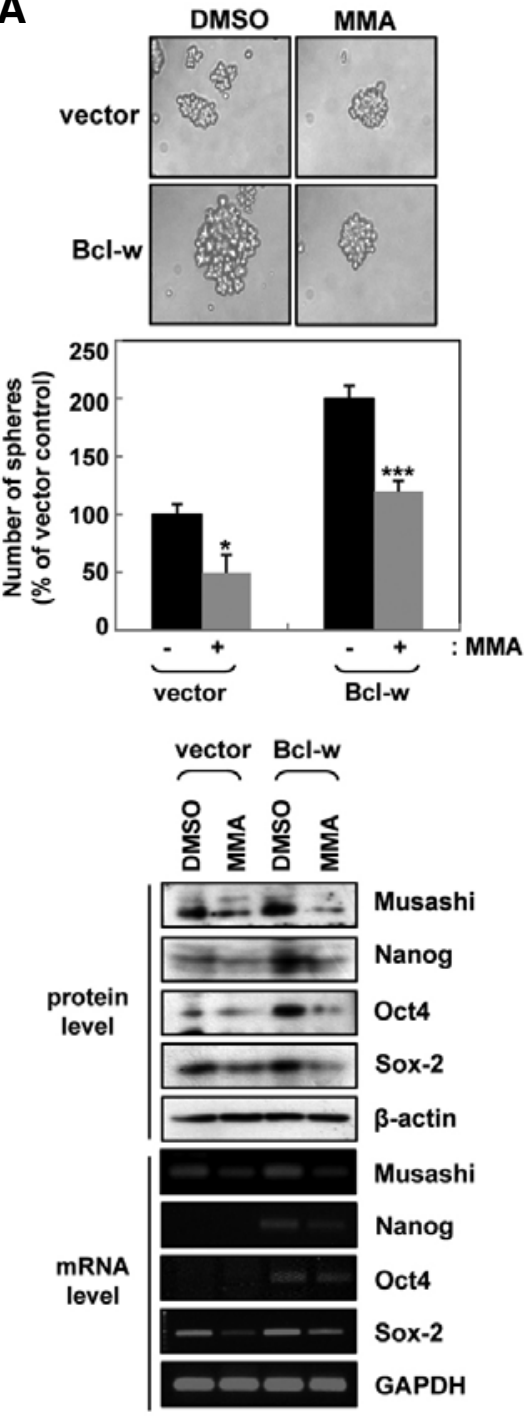

B
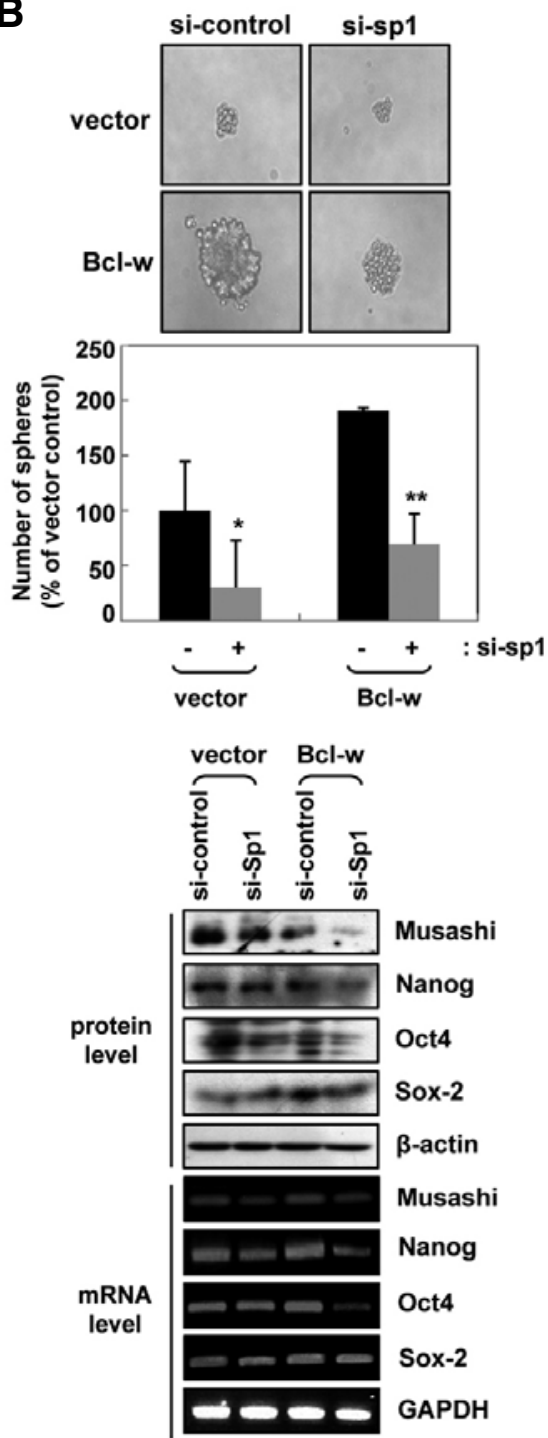

Fig. 2. Bcl-w-induced Sp1 contributes to stemness of glioblastoma cells. (A) A sphere formation assay was conducted using Sp1 inhibitor-treated and untreated cells. ${ }^{*} p<0.05 ;{ }^{* \star *} p<0.0005, \mathrm{n}$ $=5$. Protein or mRNA expression of the glioma tumor-initiating cell markers, Musashi, Nanog, Oct4 and Sox2 was compared using Western blotting or RT-PCR. (B) Sp1 siRNAs were introduced into vector or Bcl-w overexpressing cells, and a sphere formation assay, Western blotting assay and RTPCR were conducted. ${ }^{*} p<0.05 ;{ }^{* *} p<$ $0.005, n=5$. lations but also protein or mRNA expression of the glioma stem cell markers, such as Musashi, Nanog, Oct4 and Sox2. These results suggest that $\mathrm{Bcl}-\mathrm{w}$-induced $\mathrm{Sp} 1$ expression promotes cancer stem cells markers expression in the transcriptional levels.

\section{Sp1 implicates in Bcl-w-induced invasion by activating MIMP-2}

To evaluate the signaling mechanism of Sp1 on Bcl-w-induced invasion in glioma, we subsequently performed a Sp1-depletedactivation assay by pharmacological inhibition with mithramycinA $(10 \mu \mathrm{mol} / \mathrm{L})$ or RNA interference. Sp1-depleted activation not only inhibited the enzymatic activity of MMP-2, but also repressed $\mathrm{Bcl}-\mathrm{w}$-induced invasion (Figs. $3 \mathrm{~A}$ and $3 \mathrm{~B}$ ). The blockage of MMP-2 by the pharmacological inhibitor OA-Hy (20 $\mu \mathrm{mol} / \mathrm{L}$ ) or RNA interference attenuated the invasiveness of glioblastoma cells (Figs. 4A and 4B). These sequential events suggest that Bcl-w-induced Sp1 activation contributed to Bcl-winduced invasion via MMP-2 production in U251 glioma cells. Supporting these results, the overexpression of Bcl-w greatly enhanced the invasiveness and activation of signaling pathway via Sp1 and MMP-2 production in other glioma cell lines including U373 and U87MG (Lee et al., 2013). These results show that Bcl-w-induced Sp1 is implicated in the aggressive characteristics of glioma cells (Fig. 5).

\section{DISCUSSION}

$\mathrm{Bcl}-\mathrm{w}$ is expressed in a variety of cancer types, especially gastric and colorectal adenocarcinomas as well as GBM (Hoelzinger et al., 2005; Lee et al., 2003; Wilson et al., 2000). We previously reported that $\mathrm{Bcl}-\mathrm{w}$ enhances the migratory and invasive potential, as well as survivability, of gastric cancer cells (Bae et al., 2006). Also, we studied that Bcl-w promotes mesenchymal changes and invasiveness of glioblostoma cells by inducing nuclear accumulation of $\beta$-catenin (Lee et al., 2013). In addition, it has been reported that level of Bcl-w or Sp1 is overexpressed in GBM (Guan et al., 2011). However, no study has examined the relationship between Bcl-w and Sp1. We showed that Bcl-w increased Sp1 protein and mRNA expression, resulting in increased migratory and invasive potential in glioblasto- 
A
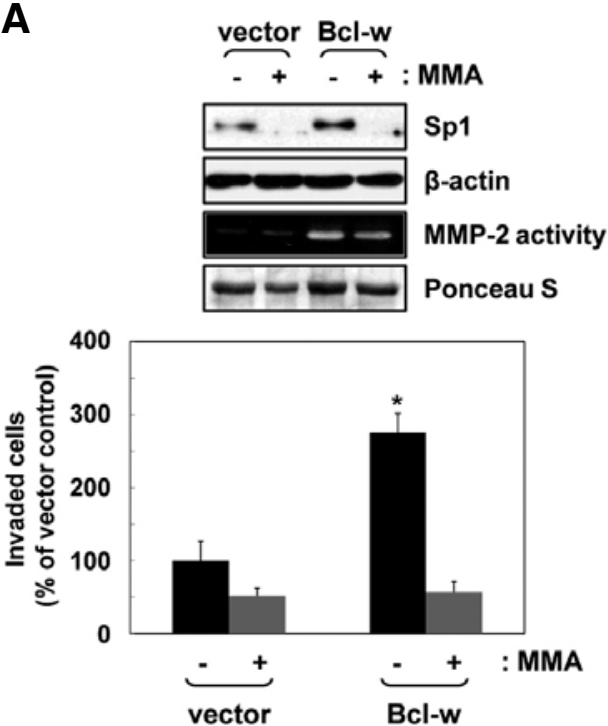

B
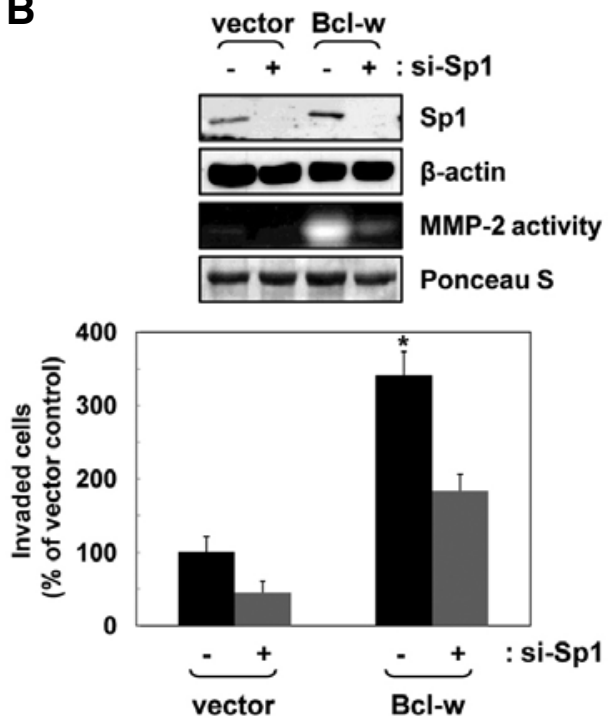

Fig. 3. Sp1 is implicated in Bclw-induced invasion upstream of MMP-2. (A) The indicated U251 cell transfectants were incubated in a serum-free medium in the presence or absence of the Sp1 inhibitor mithramycin A (MMA; $10 \mu \mathrm{mol} / \mathrm{L}$ ) for 1 or $24 \mathrm{~h}$. Expression levels and activities of Sp1 and MMP-2 were compared using Western blotting and zymography assay using $\beta$ actin as the loading control or Ponceau S staining, respectively. The invasive potential of treated cells was com-pared. ${ }^{*} p$ $<0.05$ versus untreated control, $\mathrm{n}=5$. (B) Sp1 siRNAs were introduced into vector or Bcl-w overexpressing cells, and cellular levels of Sp1 and activities of MMP-2 were compared after $24 \mathrm{~h}$ of incubation by using Western blotting and gelatin zymography assay, respectively. The invasive potential of the indicated transfectants was compared. ${ }^{*} p<0.05, \mathrm{n}=5$.
A

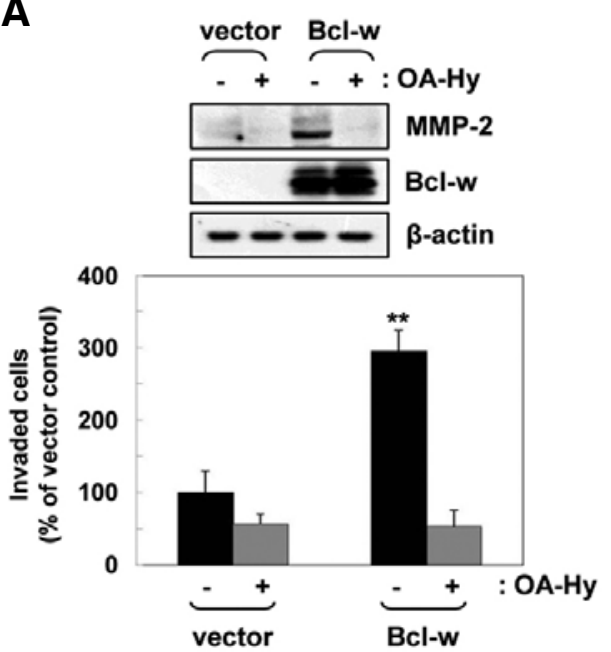

B

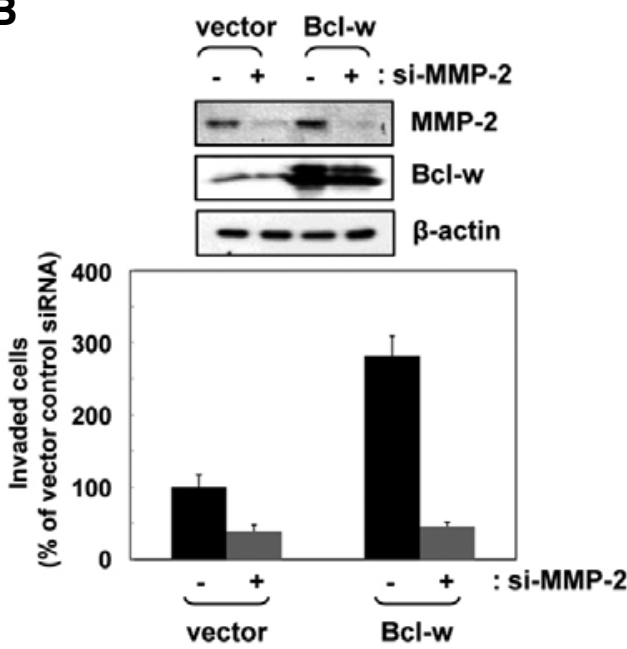

Fig. 4. Activation of MMP-2 mediates Bcl-w-induced invasion. (A) The indicated U251 cell transfectants were incubated in serum-free medium in the presence or absence of aMMP-2 inhibitor (OA-Hy; 10 $\mu \mathrm{mol} / \mathrm{L})$ for 1 or $24 \mathrm{~h}$. Expression levels of MMP-2 were compared using Western blotting. Invasion assays were performed using MMP-2 inhibitortreated and untreated cells. ${ }^{* *} p$ $<0.005$ versus untreated control, $\mathrm{n}=5$. (B) MMP-2 targeting siRNA was introduced into the indicated cells. The levels of MMP-2 were compared after 24 $\mathrm{h}$ of incubation by using Western

blotting. The invasive potential of indicated transfectants was compared. ${ }^{*} p<0.05, \mathrm{n}=5$.

ma U251 cells (Fig. 1A). Bcl-w targeting siRNA treatment of indicated glioma cells attenuated Sp1 protein and mRNA expression, thereby decreasing their invasive potential (Fig. 1B). These results strongly suggest that Bcl-w induces upregulation of Sp1 expression in the transcriptional level. It has been reported that overexpression of Sp1 leads to MMP-2 activation in gliomas and an increase in their invasiveness (Guan et al., 2011). We previously reported that Bcl-w-induced enhancement of migratory and invasive potential was accompanied by a sequential activation of several ECM-based proteinases in gastric cancer cells (Bae et al., 2006; 2009) and glioblastoma cells (Lee et al., 2013). Sp1 is transcription factor that either promotes or repress the activity of promoters of genes involved in differentiation, cell cycle and oncogenesis (Davie et al., 2008).
Sp1 expression level is often greater in various cancer tissues or cells than in normal tissues or cells (Chuang et al., 2009; Davie et al., 2008; Kong et al., 2010). Therefore, we quantitatively examined Sp1 expression levels in grade I, III and IV of glioma tissues in order to determine relationship between expression levels of Sp1 and various grades of glioma tissues. The level of Sp1 expression was upregulated in glioma grade IV compared with grade I/III in every patient examined (Fig. 1C) as well as Bcl-w expression (Lee et al., 2013). These results suggest that Bcl-w and Sp1 expression closely correlated with grading of glioma in the patients. Guan et al's group reported that Sp1 expression levels, elevated in glioma tissues and cell lines, were correlated with the WHO grading system for cancer cells (Guan et al., 2011). 


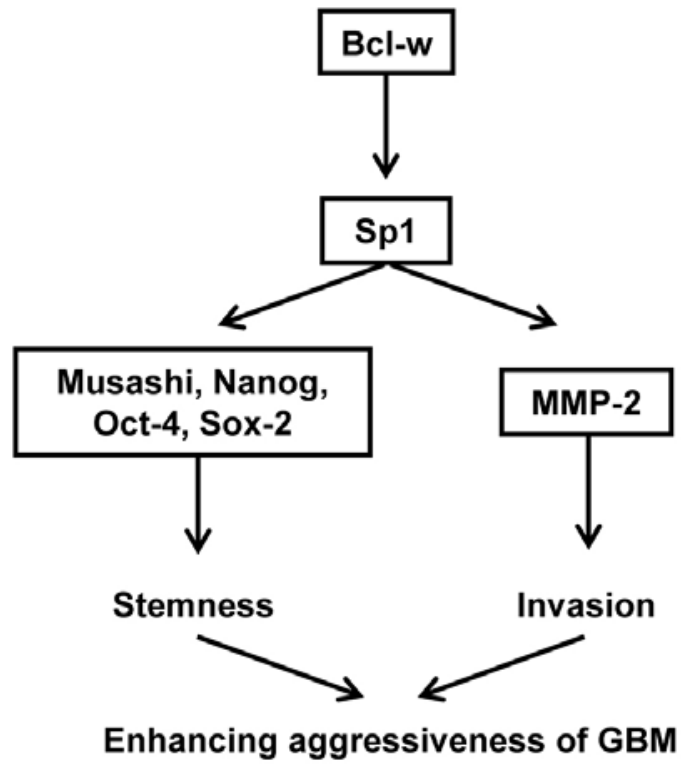

Fig. 5. Schematic diagram of the Bcl-w-induced signaling pathway by the activation of Sp1. Bcl-w enhanced the invasive potential of glioblastoma U251 cells by stimulating MMP-2 via increasing expression of the transcription factor Sp1 in the nucleus, and promoted neurosphere formation and glioma stem-like cell markers expression, Musashi, Nanog, Oct4 and Sox2. In conclusion, Bcl-w promotes the properties of GBM aggressiveness by activating Sp1.

The treatment of mithramycin A as a Sp1 inhibitor or RNA interference decreased sphere-forming glioma stem-like cell population, as well as expression protein or mRNA of the glioma stem-like cells markers, Musashi, Nanog, Oct3/4 and Sox2 (Fig. 2A). Sp1 targeting siRNA also attenuated neurosphere-forming cell population and expression protein or mRNA of the glioma stem cells markers (Fig. 2B). These results strongly suggest that Bcl-w-induced Sp1 expression upregulates cancer stem cell markers expression in the transcriptional mechanism and is closely related to the aggressiveness of GBM. Recently, evidence has been grown up that Sp1 involves in several cancerinitiating cell makers resulting in promoting cancer initiation and progression (Katoh and Katoh, 2007). Sp1 and Sp3 are important for murine Nanog gene expression (Wu and Yao, 2006). In addition, Sp1 and Sp3 directly bind to Oct4 promoter and regulate gene expression by epigenetic reprogramming (Chuang et al., 2011; Simonsson and Gurdon, 2004; Yang et al., 2005) and differentiation in bone marrow mesenchymal stem cell (Duan et al., 2012).

To further examine the mechanism by which Bcl-w-induced Sp1 expression enhanced the signaling pathway of invasiveness, down-regulation of Sp1 by the pharmacological inhibitors or small interference RNAs, was prevent to Bcl-w-induced MMP2 activities and invasion (Figs. $3 \mathrm{~A}$ and $3 \mathrm{~B}$ ). Following treatment of glioma cells with MMP-2 inhibitor (OA-Hy) or MMP-2 targeting siRNA, Bcl-w-induced tumor invasion was diminished (Figs. $4 \mathrm{~A}$ and $4 \mathrm{~B}$ ). We investigated whether Bcl-w can induce the invasiveness in other glioma cell lines, including U373 and U87MG (Lee et al., 2013). We revealed that Bcl-w-induced invasion in glioblastoma is mediated by a cellular signaling pathway that participates in sequentially upregulated Sp1and MMP-2 signaling components. These results show that Bcl-w- induced Sp1 is implicated in the aggressive characteristics of glioma cells (Fig. 5). Therefore, Sp1 may be regarded as a putative marker for aggressiveness of GBM. Future studies may investigate whether the Bcl-w-induced signaling components are related to the maintenance of stemness in GBM and how Bcl-w induces Sp1 expression.

\section{ACKNOWLEDGMENTS}

This work was supported by a grant from Nuclear Research \& Development Program (NRF-2012M2A2A7035589) and Basic Science Research Program through the National Research Foundation of Korea (NRF) (NRF-2011-0013271) funded by the Korean Ministry of Education, Science and Technology.

\section{REFERENCES}

Abdelrahim, M., Smith, R., 3rd, Burghardt, R., and Safe, S. (2004) Role of Sp proteins in regulation of vascular endothelial growth factor expression and proliferation of pancreatic cancer cells. Cancer Res. 64, 6740-6749.

Bae, I.H., Park, M.J., Yoon, S.H., Kang, S.W., Lee, S.S., Choi, K.M., and Um, H.D. (2006). Bcl-w promotes gastric cancer cell invasion by inducing matrix metalloproteinase-2 expression via phosphoinositide 3-kinase, Akt, and Sp1. Cancer Res. 66, 4991-4995.

Bae, I.H., Yoon, S.H., Lee, S.B., Park, J.K., Ho, J.N., and Um, H.D. (2009). Signaling components involved in Bcl-w-induced migration of gastric cancer cells. Cancer Lett. 277, 22-28.

Chiefari, E., Brunetti, A., Arturi, F., Bidart, J.M., Russo, D., Schlumberger, M., and Filetti, S. (2002). Increased expression of AP2 and Sp1 transcription factors in human thyroid tumors: a role in NIS expression regulation? BMC Cancer 2, 35-38.

Chuang, J.Y., Wu, C.H., Lai, M.D., Chang, W.C., and Hung, J.J. (2009). Overexpression of Sp1 leads to p53-dependent apoptosis in cancer cells. Int. J. Cancer 125, 2066-2076.

Chuang, Y.S., Huang, W.H., Park, S.W., Persaud, S.D., Hung, C.H., Ho, P.C., and Wei, L.N. (2011). Promyelocytic leukemia protein in retinoic acid-induced chromatin remodeling of Oct4 gene promoter. Stem Cells 29, 660-669.

Davie, J.R., He, S., Li, L., Sekhavat, A., Espino, P., Drobic, B., Dunn, K.L., Sun, J.M., Chen, H.Y., Yu, J., et al. (2008). Nuclear organization and chromatin dynamics-Sp1, Sp3 and histone deacetylases. Adv. Enzyme Regul. 48,189-208.

Duan, P., Zhang, Y., Han, X., Liu, J., Yan, W., and Xing, Y. (2012). Effect of neuronal induction on NSE, Tau, and Oct4 promoter methylation in bone marrow mesenchymal stem cells. In vitro cellular \& developmental biology. Animal 48, 251-258.

Furnari, F.B., Fenton, T., Bachoo, R.M., Mukasa, A., Stommel, J.M., Stegh, A., Hahn, W.C., Ligon, K.L., Louis, D.N., Brennan, C., et al. (2007). Malignant astrocytic glioma: genetics, biology, and paths to treatment. Genes Dev. 21, 2683-2710.

Guan, H., Cai, J., Zhang, N., Wu, J., Yuan, J., Li, J., and Li, M. (2011). Sp1 is upregulated in human glioma, promotes MMP-2mediated cell invasion and predicts poor clinical outcome. Int. J. Cancer 130, 593-601.

Hoelzinger, D.B., Mariani, L., Weis, J., Woyke, T., Berens, T.J., McDonough, W.S., Sloan, A., Coons, S.W., and Berens, M.E. (2005). Gene expression profile of glioblastoma multiforme invasive phenotype points to new therapeutic targets. Neoplasia 7, 7-16.

Jungert, K., Buck, A., von Wichert, G., Adler, G., Konig, A., Buchholz, M., Gress, T.M., and Ellenrieder, V. (2007). Sp1 is required for transforming growth factor-beta-induced mesenchymal transition and migration in pancreatic cancer cells. Cancer Res. 67, 15631570.

Katoh, Y., and Katoh, M. (2007). Conserved POU-binding site linked to SP1-binding site within FZD5 promoter: Transcriptional mechanisms of FZD5 in undifferentiated human ES cells, fetal liver/spleen, adult colon, pancreatic islet, and diffuse-type gastric cancer. Int. J. Oncol. 30, 751-755.

Kong, L.M., Liao, C.G., Fei, F., Guo, X., Xing, J.L., and Chen, Z.N (2010). Transcription factor Sp1 regulates expression of cancerassociated molecule CD147 in human lung cancer. Cancer Sci. 101, 1463-1470. 
Kumar, A.P., and Butler, A.P. (1999). Enhanced Sp1 DNA-binding activity in murine keratinocyte cell lines and epidermal tumors. Cancer Lett. 137, 159-165.

Lee, H.W., Lee, S.S., Lee, S.J., and Um, H.D. (2003). Bcl-w is expressed in a majority of infiltrative gastric adenocarcinomas and suppresses the cancer cell death by blocking stress-activated protein kinase/c-Jun NH2-terminal kinase activation. Cancer Res. 63, 1093-1100.

Lee, W.S., Woo, E.Y., Kwon, J., Park, M.J., Lee, J.S., Han, Y.H., and Bae, I.H. (2013). Bcl-w enhances mesenchymal changes and invasiveness of glioblastoma cells by inducing nuclear accumulation of $\beta$-catenin. PLoS One 8 , e68030.

Lou, Z., O’Reilly, S., Liang, H., Maher, V.M., Sleight, S.D., and McCormick, J.J. (2005). Down-regulation of overexpressed sp1 protein in human fibrosarcoma cell lines inhibits tumor formation. Cancer Res. 65, 1007-1017.

Safe, S., and Abdelrahim, M. (2005). Sp transcription factor family and its role in cancer. Eur. J. Cancer 41, 2438-2448.

Shi, Q., Le, X., Abbruzzese, J.L., Peng, Z., Qian, C.N., Tang, H., Xiong, Q., Wang, B., Li, X.C., and Xie, K. (2001). Constitutive Sp1 activity is essential for differential constitutive expression of vascular endothelial growth factor in human pancreatic adenocarcinoma. Cancer Res. 61, 4143-4154.

Shin, J.E., Park, S.H., and Jang, Y.K. (2011). Epigenetic up-regulation of leukemia inhibitory factor (LIF) gene during the progression to breast cancer. Mol. Cells 31, 181-189.

Simonsson, S., and Gurdon, J. (2004). DNA demethylation is necessary for the epigenetic reprogramming of somatic cell nuclei. Nat. Cell Biol. 6, 984-990.

Wang, L., Wei, D., Huang, S., Peng, Z., Le, X., Wu, T.T., Yao, J., Ajani, J., and Xie, K. (2003). Transcription factor Sp1 expression is a significant predictor of survival in human gastric cancer. Clin.
Cancer Res. 9, 6371-6380.

Wang, L., Guan, X., Gong, W., Yao, J., Peng, Z., Wei, D., Wu, T.T. Huang, S., and Xie, K. (2005). Altered expression of transcription factor Sp1 critically impacts the angiogenic phenotype of human gastric cancer. Clin. Exp. Metastasis 22, 205-213.

Wei, D., Wang, L., He, Y., Xiong, H.Q., Abbruzzese, J.L., and Xie, K. (2004). Celecoxib inhibits vascular endothelial growth factor expression in and reduces angiogenesis and metastasis of human pancreatic cancer via suppression of $\mathrm{Sp} 1$ transcription factor activity. Cancer Res. 64, 2030-2038.

Wilson, J.W., Nostro, M.C., Balzi, M., Faraoni, P., Cianchi, F., Becciolini, A., and Potten, C.S. (2000). Bcl-w expression in colorectal adenocarcinoma. Br. J. Cancer 82, 178-185.

Wu, D.Y., and Yao, Z. (2006). Functional analysis of two Sp1/Sp3 binding sites in murine Nanog gene promoter. Cell Res. 16, 319322.

Yang, H.M., Do, H.J., Oh, J.H., Kim, J.H., Choi, S.Y., Cha, K.Y., and Chung, H.M. (2005). Characterization of putative cis-regulatory elements that control the transcriptional activity of the human Oct4 promoter. J. Cell Biochem. 96, 821-830.

Yao, J.C., Wang, L., Wei, D., Gong, W., Hassan, M., Wu, T.T., Mansfield, P., Ajani, J., and Xie, K. (2004). Association between expression of transcription factor Sp1 and increased vascular endothelial growth factor expression, advanced stage, and poo survival in patients with resected gastric cancer. Clin. Cancer Res. 10, 4109-4117.

Zannetti, A., Del Vecchio, S., Carriero, M.V., Fonti, R., Franco, P., Botti, G., D'Aiuto, G., Stoppelli, M.P., and Salvatore, M. (2000). Coordinate up-regulation of Sp1 DNA-binding activity and urokinase receptor expression in breast carcinoma. Cancer Res. 60, 1546-1551. 